Document downloaded from:

http://hdl.handle.net/10251/169184

This paper must be cited as:

Zavala-Alcívar, A.; Verdecho Sáez, MJ.; Alfaro Saiz, JJ. (2020). Resilient Strategies and Sustainability in Agri-Food Supply Chains in the Face of High-Risk Events. IFIP Advances in Information and Communication Technology. 598:560-570. https://doi.org/10.1007/978-3030-62412-5_46

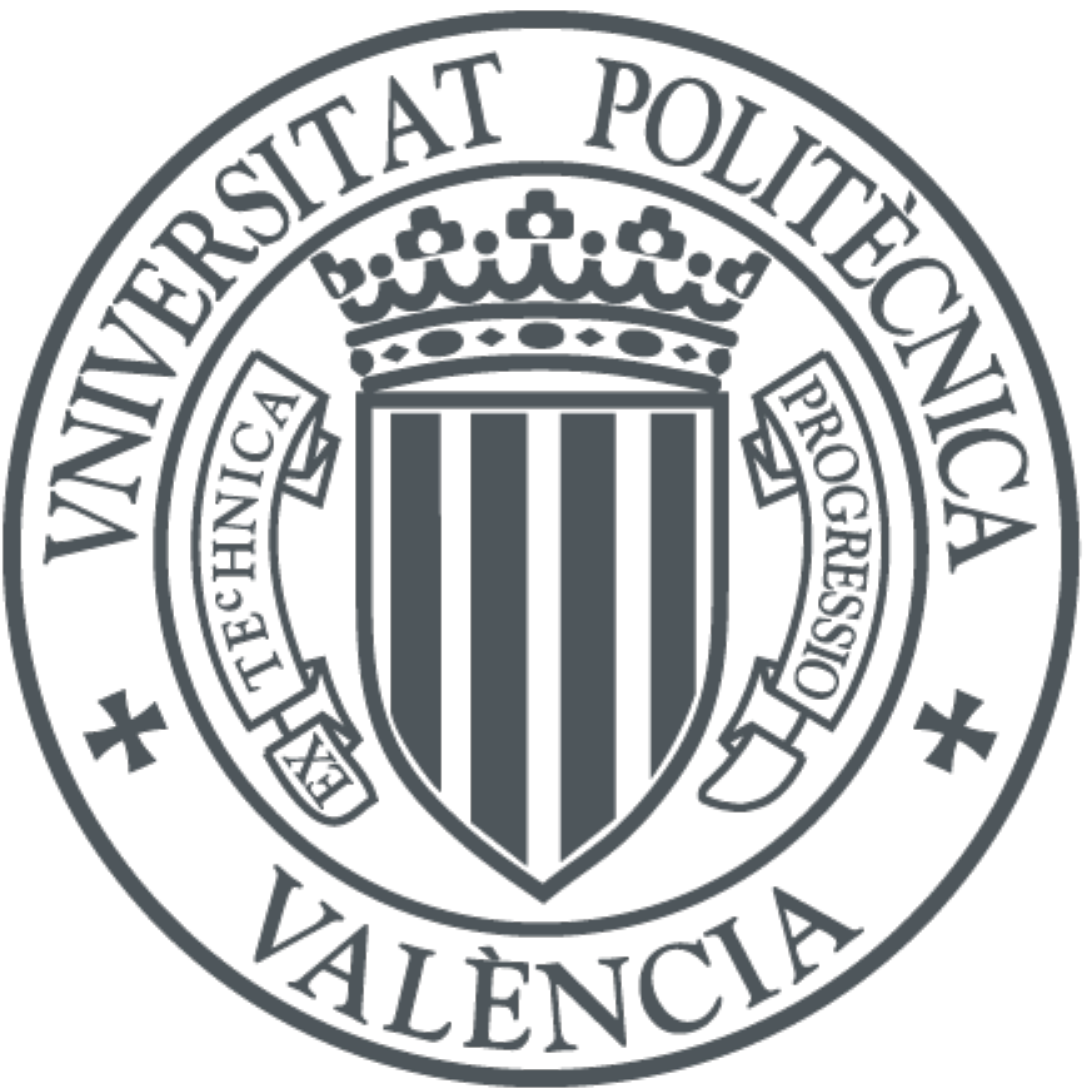

The final publication is available at

https://doi.org/10.1007/978-3-030-62412-5_46

Copyright Springer

Additional Information 


\title{
Resilient strategies and sustainability in agri-food supply chains in the face of high-risk events
}

\author{
Antonio Zavala-Alcívar ${ }^{1}$, María-José Verdecho ${ }^{2}$ and Juan-José Alfaro-Saiz ${ }^{2}$, \\ ${ }^{1}$ Faculty of Industrial Engineering, Universidad Laica Eloy Alfaro de Manabí, Manta \\ 130214, Ecuador \\ ${ }^{2}$ Research Centre on Production Management and Engineering (CIGIP), Universitat \\ Politècnica de València, Camino de Vera S/N, Valencia, 46022 Spain
}

antonio.zavala@uleam.edu.ec; mverdecho@cigip.upv.es; jalfaro@cigip.upv.es

\begin{abstract}
Agri-food supply chains (AFSCs) are very vulnerable to high risks such as pandemics, causing economic and social impacts mainly on the most vulnerable population. Thus, it is a priority to implement resilient strategies that enable AFSCs to resist, respond and adapt to new market challenges. At the same time, implementing resilient strategies impact on the social, economic and environmental dimensions of sustainability. The objective of this paper is twofold: analyze resilient strategies on AFSCs in the literature and identify how these resilient strategies applied in the face of high risks affect the achievement of sustainability dimensions. The analysis of the articles is carried out in three points: consequences faced by agri-food supply chains due to high risks, strategies applicable in AFSCs, and relationship between resilient strategies and the achievement of sustainability dimensions.
\end{abstract}

Keywords: agri-food supply chain, sustainability, resilience, high-risk events, COVID-19

\section{Introduction}

Throughout history, humanity has been challenged by disease outbreaks that have had unprecedented negative consequences on society, severely affecting and modifying common behavior and habits. The response of the countries affected by the COVID19 pandemic is focused on rules such as movement restriction, social distancing, and border closures[1], generating deep and severe economic implications that affect the operations of the supply chains [2].

The agri-food supply chain (AFSC) is critical to the economic, environmental and social development of countries, and its disruption minimizes the achievement of food security, affecting mainly the most vulnerable populations [3]. Currently, it is one of the chains most affected by the COVID-19 pandemic due to the adaptive strategies to the interruptions it has experienced: panic buying, changes in food purchasing patterns, labor shortages due to social distancing and interruptions in transportation and supplies [2]. The severe effects of this challenge require different strategies and actions, including robust resilience strategies that minimize the ripple effect in the 
supply chain [4]. These applicable resilient strategies can affect the achievement of sustainability dimensions within supply chains [5].

The literature presents some studies that deal with the supply chain under high risks: influenza [6]-[9], Ebola [10], cholera [11]-[13]. These studies have focused mainly on the health sector, considering the analysis of types of procurement policies, limited resource allocation, distribution of medicines to vulnerable areas, and hospital and health facility responses [2]. In other words, actions taken concurrently with the interruption that mainly allow the primary care system to remain operational. Similarly, considering COVID-19 pandemic, research has been conducted to estimate the risks and possible effects on supply chains [2], [5], [14]. The analysis of resilient actions applicable in conjunction with sustainability objectives has been considered by [15]. However, this research does not generate an analysis specific to AFSCs.

Within the agri-food area, [16] focuses its analysis on supply chains under high risk from logistics management. [17], [18] analyze the AFSCs as a mechanism to minimize the spread of disease. However, these studies do not respond to a global analysis of resilient supply chain actions that should be applied when disruption occur and how they affect sustainability objectives. The purpose of this paper is to address this research gap. Then, the objective of this paper is twofold: analyze resilient strategies on AFSCs in the literature and identify how these resilient strategies applied in the face of high risks affect the achievement of sustainability dimensions.

The structure of this paper is as follows. First, the search parameters are defined. Then, the analysis of the articles is carried out in three points: consequences faced by AFSCs due to high risks, strategies applicable in AFSCs, and relationships between resilient strategies and the achievement of sustainability dimensions. Finally, conclusions are drawn.

\section{Literature review}

\subsection{Search criteria}

The methodological approach applied in this research is the Systematic Literature Review (SLR) proposed by [19]. The procedure applied consists of formulation of research questions; location of literature; selection; analysis and synthesis, and report of results. Considering the objective of this research, the following questions serve as a starting point: What resilient strategies have AFSCs applied to address high risks such as pandemics? How do resilient strategies applied by AFSCs affect the achievement of their sustainability objectives? The keyword used were: "resilience management", "high risk" and "agri-food supply chain". This allowed the structuring of search strings with these keywords, for example: ("outbreak*" OR "pandemic*" OR "epidemic*" OR "disease*") AND ("resilien*) AND ("supply chain") AND ("agri-food" OR "food" OR "agriculture*" OR "agribusiness"). The database used was Scopus. Initially, 75 articles were obtained. Later, results were filtered using the following criteria: English language, peer-reviewed indexed journals and time interval from 2000. This resulted in 25 articles, which are discussed below. 


\subsection{Results and discussion}

\subsubsection{Consequences of high-risk events in AFSCs}

In daily operations, members of supply chains suffer disruptive events that affect their normal operation and cause unforeseen changes and impacts on other members [20], [21]. The level of vulnerability of the supply chain and the type of risk that occurs has to be considered to analyze the level of impact [22]. Pandemics are classified as low probability events with high consequences (LPHC), and therefore have a higher level of impact on supply chains [23], [24]. The lack of capacity in the chain to anticipate or foresee the occurrence of disruption makes their consequences of high impact and even decisive for the continuity of the business [25].

The agri-food supply chain is highly vulnerable, having to adapt quickly to a disruptive event [1] to ensure food security [3]. While the COVID-19 pandemic is deploying, AFSCs have shown this capacity to recover and adapt to disruptive events on the demand and supply side.

The restrictions applied by the states to deal with the COVID-19 pandemic and the disorder in the purchasing attitude of consumers, drastically affected the operations of AFSCs. In the early stage of the social distancing applied in most countries [1], it caused a short-term shortage of supplies mainly due to consumer hoarding [3], [26]. This was exacerbated for perishable items where the food distribution system is based on just-in-time manufacturing and delivery to ensure consumption [27].

Labor shortages due to worker illness, self-isolation, or movement restrictions lead to supply-side disruption. Companies adapt their production system using alternatives such as half shifts, temporary employees, temporary closures of their manufacturing lines, or modification of their products to fit the market [28]. The closure of nonessential businesses during the disruption creates a pool of unemployed labor, which is mainly transferred to essential activities such as food distribution tasks [3]. The closure of borders increased the pressure for shortages, with supply chains having to adapt to new relocation protocols and creating unavoidable delays [1], although the food relocation system is guaranteed.

The consequences of disruption are also reflected in the medium and long term, where there is a growth in the online grocery delivery sector and a prioritization of local food supply chains [27]. AFSCs must adapt to these new consumer requirements.

\subsubsection{Resilient strategies applied in AFSCs affected by high-risk events}

It is of utmost importance for the recovery of normality in a supply chain to establish the appropriate resilient strategies to deal with serious disruptive events. Strategies can be divided into three types: (1) proactive, (2) concurrent and (3) reactive depending on the phase of the disruption [29].

Proactive strategies are developed in the stage before the occurrence of the disruptive event and enable the prevention capability of the supply chain to be activated. To establish preventive strategies, it is necessary to consider the stakeholders, the risks, the vulnerability of the nodes and the possible results of the 
disturbances [30]. Concurrent strategies allow for resistance and rapid response when the interruption occurs [31]. Their main objective is to provide continuity of supply chain operations, although in many cases, the consequences of disruption make business continuity impossible. And reactive strategies correspond to strategies after surviving the disruptive event, i.e., they include recovery, learning, continuous improvement and adaptation to the new market reality, i.e., returning to the original state of the supply chain or moving to a better state [32], [33]. Table 1 shows the main strategies applied in the articles analyzed. The strategies are classified according to the stage of implementation (proactive $(\mathrm{P})$, concurrent $(\mathrm{C})$ or reactive $(\mathrm{R})$ ) and the type of risk category (supply (S) or demand (D)) in the supply chain.

Table 1: Principal strategies depending on the implementation stage and risk category.

\begin{tabular}{|c|c|c|c|c|c|c|}
\hline \multirow[t]{2}{*}{ Strategies } & \multirow[t]{2}{*}{ Articles } & \multicolumn{3}{|c|}{$\begin{array}{l}\text { Implementation } \\
\text { stage }\end{array}$} & \multicolumn{2}{|c|}{$\begin{array}{c}\text { Risk } \\
\text { category }\end{array}$} \\
\hline & & $\mathrm{P}$ & $\mathrm{C}$ & $\mathrm{R}$ & $\mathrm{S}$ & D \\
\hline $\begin{array}{l}\text { 1) Policies for stock security, redundancy, and } \\
\text { diversification in the stocking of raw materials }\end{array}$ & {$[33]-[36]$} & $\checkmark$ & & & $\sqrt{ }$ & \\
\hline $\begin{array}{l}\text { 2) Select flexible and agile suppliers with product } \\
\text { support capabilities and geographic dispersion. }\end{array}$ & {$[27],[33]-[39]$} & $\checkmark$ & & & $\checkmark$ & \\
\hline $\begin{array}{l}\text { 3) Implementation of special supplier contracting } \\
\text { methodology for critical suppliers, multiple suppliers } \\
\text { and substitute suppliers. }\end{array}$ & $\begin{array}{l}{[27],[33]-[35]} \\
{[37]}\end{array}$ & $\checkmark$ & $\checkmark$ & & $\checkmark$ & \\
\hline $\begin{array}{l}\text { 4) Fortification strategies in supply chain design } \\
\text { allowing for production flexibility and reprogramming } \\
\text { of production }\end{array}$ & $\begin{array}{l}{[37],[38],[40],} \\
{[41]}\end{array}$ & $\checkmark$ & $\checkmark$ & $\checkmark$ & & $\checkmark$ \\
\hline $\begin{array}{l}\text { 5) Increase robustness by introducing redundancy in } \\
\text { production, excessive inventories and safety stocks }\end{array}$ & {$[42]$} & & $\checkmark$ & & $\checkmark$ & \\
\hline $\begin{array}{l}\text { 6) Establishment of multiple supply and delivery } \\
\text { routes; dual supply. Direct distribution to the } \\
\text { customer }\end{array}$ & $\begin{array}{l}{[26],[37],[39],} \\
{[43]}\end{array}$ & & $\checkmark$ & $\checkmark$ & $\checkmark$ & $\checkmark$ \\
\hline $\begin{array}{l}\text { 7) Integration of logistics capabilities with those of its } \\
\text { strategic supply chain local partners }\end{array}$ & $\begin{array}{l}{[1],[26],[38]} \\
{[42]-[44]}\end{array}$ & & $\checkmark$ & $\checkmark$ & $\checkmark$ & \\
\hline $\begin{array}{l}\text { 8) Multiple methods for collaborative forecasting, } \\
\text { customer data collection and immediate information } \\
\text { exchange. }\end{array}$ & {$[35],[36],[41]$} & & $\checkmark$ & $\checkmark$ & & $\checkmark$ \\
\hline $\begin{array}{l}\text { 9) Interoperability of information systems; visibility } \\
\text { and shared information for effective collaborative } \\
\text { relationships and shared decision making. }\end{array}$ & $\begin{array}{l}{[35],[36],[38]-} \\
{[41],[43]-[46]}\end{array}$ & $\checkmark$ & $\checkmark$ & $\checkmark$ & $\checkmark$ & $\checkmark$ \\
\hline $\begin{array}{l}\text { 10) Contingency plan and business reactivation; } \\
\text { insurance and public-private strategic collaboration. }\end{array}$ & $\begin{array}{l}{[26],[36],[39]} \\
{[45]}\end{array}$ & $\checkmark$ & $\checkmark$ & $\checkmark$ & $\checkmark$ & $\checkmark$ \\
\hline $\begin{array}{l}\text { 11) Redesigning the supply chain towards market } \\
\text { adaptation }\end{array}$ & $\begin{array}{l}{[36],[37],[39]} \\
{[41],[43],[45]}\end{array}$ & & & $\checkmark$ & $\checkmark$ & $\checkmark$ \\
\hline
\end{tabular}

P: proactive; C: concurrent; R: reactive; S: supply; D: demand

Considering the supplier-manufacturer relationship to be paramount, strategies of stock security, redundancy, and diversification in the stocking of raw materials [33][36], select flexible and agile suppliers with product support capabilities and geographic dispersion [27], [33]-[39] and implementation of special supplier contracting methodology for critical suppliers, multiple suppliers and substitute 
suppliers [27], [33]-[35], [37]. These strategies should be implemented at the prevention stage considering the vulnerability of the focal company and its suppliers [21].

Considering the focal company, fortification strategies in supply chain design that allow for production flexibility and production rescheduling [37], [38], [40], [41] and that increase robustness by introducing production redundancy, excessive inventories and security stocks [42] are proposed. These strategies allow supporting the disruptive event and keeping the productive process adapted to the new reality. These operations depend on the level of connection and flexible commitment of the suppliers.

In the supplier-manufacturer-distributor relationships, the literature analyze strategies of establishment of multiple supply and delivery routes, dual supply, direct distribution to the customer [26], [37], [39], [43] and integration of logistics capabilities with those of its strategic supply chain local partners [1], [26], [38], [42][44]. A relevant characteristic is the use of local companies for the supply of products.

The customer is also considered in resilient strategies when disruptive events occur. Research proposes to establish multiple methods for collaborative forecasting, customer data collection and immediate information exchange [35], [36], [41]. These strategies are applicable in the concurrent and reactive stage of the interruption, considering the survival level of the supply chain. Another strategy of great interest is the interoperability of information systems for efficient, timely and joint decisionmaking by members of the supply chain [35], [36], [38]-[41], [43]-[46]. The adaptation to the new market requirements is applied as a reactive strategy considering a restructuring of the value chain to meet the new consumer requirements [36], [37], [39], [41], [43], [45]. This adaptation depends on the contingency plan and the reactivation of the business, with the public-private strategic partnership being essential to guarantee the continuity of the business [26], [36], [39], [45].

Some strategies remain active during all stages of the disruptive event, generating a continuous improvement cycle in the companies [4]. That is the reason why they are classified in the three stages. The strategies planned in the proactive stage can be implemented in this same stage or when a disruptive event occurs, and it is necessary to monitor their results in the concurrent and reactive stage to generate improvement during and after the disruptive event [30]. These strategies should be considered as interrelated actions, since the consequences of one type of strategy can also impact on the strengthening of others [41], [47].

It should be noted that the consequences of the disruption analyzed envisage a partial continuity of supply chain operations and do not encompass simultaneous interruptions on the supply and demand side for an indefinite period.

\subsubsection{Relationships between strategies to increase resilience and sustainability dimensions}

Resilient strategies applied when serious disruptive events occur, affects in greater proportion the achievement of the sustainability dimensions. Also, there are situations where sustainability strategies influence the ability of the supply chain to address unplanned disruptions [41], although this last issue is not analyzed in this paper.

Increasing supply chain sustainability imply pursuing three types of sustainability dimensions: economic, environmental and social. The economic dimension is 
extended in some works, e.g. [48]-[50], to include other classical business criteria conforming the economic-business dimension. Thus, this dimension focuses on criteria such as organization and strategy (OS), financial situation (FS), technological integration (TI) and product quality (PQ). The environmental dimension refers to criteria such as the rational consumption of resources (RCR), pollution control (PC) and waste management (WM). The social dimension considers stakeholder participation (SP), occupational health and safety (OHS), staff training and satisfaction (STS), and community commitment and support (CCS) [51]-[53].

Table 2 present a summary of the relationship between strategies to increase resilience and sustainability dimensions. Relationships can be positive when applying the strategy produces a positive impact on the sustainability dimension or negative when applying the strategy produces a negative impact on the sustainability dimension. Resilient strategies analyzed mainly affect the economic-business and environmental dimensions although they also impact the social dimension. In the economic-business dimension, the increase in costs translates into a negative impact on the financial situation of the company. In the environmental dimension, resilient strategies have the greatest impact on increasing resource use and waste management in the supply, production and distribution process. In the social dimension, the stakeholder participation is the subdimension that gets the most number of impacts.

Table 2: Relationships between strategies to increase resilience and the sustainability dimensions.

\begin{tabular}{|c|c|c|c|c|c|c|c|c|c|c|c|}
\hline \multirow{2}{*}{ Strategies } & \multicolumn{4}{|c|}{ Economic-Business } & \multicolumn{3}{|c|}{ Environmental } & \multicolumn{4}{|c|}{ Social } \\
\hline & OS & $\overline{F S}$ & TI & PQ & $\overline{\mathrm{RCR}}$ & $\overline{\mathrm{PC}}$ & WM & $\overline{\mathrm{SP}}$ & OHS & STS & $\mathrm{CCS}$ \\
\hline 1) & $\mathrm{X}$ & $\mathrm{X}$ & & $\mathrm{X}$ & $\mathrm{X}$ & & $\mathrm{X}$ & & & & \\
\hline 2) & & $X$ & & $X$ & X & & $X$ & $X$ & & & $X$ \\
\hline 3) & & $X$ & & X & $X$ & & $X$ & & & & \\
\hline 4) & & $X$ & & X & X & $X$ & X & & $X$ & $X$ & \\
\hline 5) & & $X$ & & X & X & $X$ & X & & X & X & \\
\hline 6) & & $X$ & & $X$ & X & & X & & & & \\
\hline 7) & & $X$ & & & & & $X$ & $\checkmark$ & & & $\checkmark$ \\
\hline 8) & & $\mathrm{X}$ & $\checkmark$ & & & & & $\checkmark$ & & & \\
\hline 9) & & $\mathrm{X}$ & $\checkmark$ & $\checkmark$ & $\checkmark$ & & $\checkmark$ & $\checkmark$ & & & \\
\hline 10) & $\checkmark$ & $\mathrm{X}$ & $\checkmark$ & & & & & $\checkmark$ & $\checkmark$ & $\checkmark$ & $\checkmark$ \\
\hline 11) & $\checkmark$ & $\mathrm{X}$ & & & & & & $\checkmark$ & $\checkmark$ & $\sqrt{ }$ & $\checkmark$ \\
\hline
\end{tabular}

$\checkmark$ : positive; $X$ : negative

Strategies $1,2,3,6$, and 7 characterized by flexibility, redundancy, and robustness of the supply and distribution process, increase the use of resources within the supply chain. Maintaining inventories to cope with disruptive events generates increased costs, and might reduce product quality due to expiration and increased stock management. Furthermore, AFSCs have a high rate of deterioration, especially of perishable products, and together with uncertain demand and transportation problems, this results in a percentage of items that cannot reach consumers and become waste [54]. If the product is not delivered to customers in time, it is no longer valuable and its subsequent disposal causes contamination. This also affects the social side of 
sustainability because it reduces the principle of food security for stakeholders, affecting mainly the most vulnerable population.

Sustainable procurement imply the need to evaluate suppliers and work with those with the best sustainable performance [55]. This strategy may generate an unintended inability to change between suppliers where the supply chain tries to ensure continuity, being a constraint. Applying the resilient strategy of maintaining geographically dispersed suppliers and flexible contracting policies affects the social dimension because the company will not contract exclusively with local suppliers. This situation is to be analyzed, given that if in the initial stage of the disruption total closure of borders occurs, it will affect the continuity of geographically dispersed supply.

Strategies 4 and 5 that establish flexibility, redundancy, robustness and reprogramming of production generate increased costs, greater pollution, and waste management. These strategies considered not clean, allow to face the interruption and respond immediately to the new market requirements. In applying these strategies, supply chains must take measures to ensure the safety and health of workers [28], [41], by prevention training and adapting jobs to biosafety needs. This changes the criteria for OHS and STS.

It is important to analyze the evolution of consumers, as established in strategy 8 , mainly in the consumer confidence that allows to include safe redundant strategies in points close to customers and avoid increased costs and waste. This increases costs in the company because of the technological level required to implement it.

Some strategies do not conflict with sustainable criteria. Interoperability of information systems, visibility, and information sharing for effective collaboration and joint decision making (strategy 9), business and contingency planning (strategy 10), and subsequent redesign of the supply chain (strategy 11) are necessary to maintain continuity of operations and market adaptability [14], [15]. These strategies, although they generate associated costs, generate a positive relationship with the social criteria of sustainability, because of the use of local labor. It is necessary to strengthen public-private relations to guarantee the continuity of food security, mainly with the supply of the most vulnerable.

The strategies $6,7,8$ and 9, of balancing global supply with local supply and the adaptation of technological strategies to maintain contact with the client allow social criteria of sustainability to be achieved. These strategies allow supply chains to have a more direct link with stakeholders and promote community engagement and support. These practices benefit the resilient and sustainable criteria of supply chains. It is necessary to increase the culture of development and dynamic capacities of workers as a multifunctional workforce and the formation of interdisciplinary groups to identify vulnerable processes in the supply chain [28], [56].

\section{Conclusion}

AFSC is being severely affected by the consequences of the COVID-19 pandemic, mainly in the supply of basic food items generating economic-business, 
environmental and social impacts in society. AFSC is vulnerable because of the high rate of deterioration of its products, its priority in society, the uncertainty of demand and distribution problems. It must generate resilient responses to face this type of interruptions that allow it to resist the disruptive event and continue with its operations adapted to the requirements of the market.

Previous literature develops an analysis of resilient strategies applicable when a serious disruptive event occurs in AFSCs but it overlooks to analyze the impact of these strategies on the sustainability dimensions. This analysis is essential for establishing business designs and policies that include both aspects and allow for business continuity.

This paper analyzes the pandemic risk in AFSCs, its consequences, the applicable strategies depending on the stage of implementation and supply/demand side. It also establishes the main relationships between the strategies to increase resilience and the dimensions of sustainability. The analysis showed a greater impact on the economicbusiness and environmental dimensions of sustainability, characterized by the flexibility, redundancy, and robustness of resilient strategies. AFSCs must redesign and adapt their value chain with short-term priorities such as adapting the production, distribution, and movement of their workers. Short food supply chains and local productions generate a rapid response to the presented disruption and approach to the consumer. In the long term, strategies that encourage digital preparedness and data sharing must be included. Digitization of the supply chain, building contingency plans and strategic public-private partnerships improve the quality of response to disruptions related to major disruptions without diminishing the achievement of sustainable dimensions.

As further research it is the simulation of the implementation of the resilient strategies found in the literature that will allow to analyze their impacts on the economic-business, social and environmental dimensions of sustainability in a more specific way. In addition, human talent management during major disruptions such as pandemics has not been addressed in the AFSC literature. Strategies should be established to promote the development and dynamic capabilities of workers to increase their multi-functionality to cope with, for example, reduced working hours.

\section{Acknowledgements}

Authors of this publication acknowledge the contribution of the Project 691249, RUC-APS "Enhancing and implementing Knowledge based ICT solutions within high Risk and Uncertain Conditions for Agriculture Production Systems" (www.rucaps.eu), funded by the European Union under their funding scheme H2020-MSCARISE-2015.

\section{References}

1. Gray, R.: Agriculture, transportation, and the COVID-19 crisis," Can. J. Agric. Econ., 1--5 (2020). 
2. Queiroz, M., Ivanov, D., Dolgui, A., Fosso, S.: Impacts of epidemic outbreaks on supply chains: mapping a research agenda amid the COVID-19 pandemic through a structured literature review, no. 0123456789. Springer US (2020).

3. Hobbs, J.: Food supply chains during the COVID-19 pandemic. Can. J. Agric. Econ. 1--6 (2020).

4. Shashi, P., Centobelli, P., Cerchione, R., Ertz, M.:Managing supply chain resilience to pursue business and environmental strategies. Bus. Strateg. Environ (2019).

5. Ivanov, D.: Predicting the impacts of epidemic outbreaks on global supply chains: A simulation-based analysis on the coronavirus outbreak (COVID-19/SARS-CoV-2) case. Transp. Res. Part E Logist. Transp. Rev. 136, 101922 (2020).

6. Mamani, H., Chick, S. E., Simchi-Levi, D.: A Game-Theoretic Model of International Influenza Vaccination Coordination. Manage. Sci. 59-7, 1650--1670 (2013).

7. Liu, M., Zhang, D.: A dynamic logistics model for medical resources allocation in an epidemic control with demand forecast updating. J. Oper. Res. Soc. 67, 841--852 (2016).

8. Hessel, L.: Pandemic influenza vaccines: meeting the supply, distribution and deployment challenges. Influenza Other Respi. Viruses, 3, 165--170 (2009).

9. Orenstein, W., Schaffner, W.: Lessons Learned: Role of Influenza Vaccine Production, Distribution, Supply, and Demand-What It Means for the Provider. Am. J. Med. 121, pp. S22--S27 (2008).

10. Büyüktahtakın, I., Des-Bordes, E., Kıbış, E.: A new epidemics-logistics model: Insights into controlling the Ebola virus disease in West Africa. Eur. J. Oper. Res. 26, 1046--1063 (2018).

11. Anparasan, A., Lejeune, M.: Analyzing the response to epidemics: concept of evidence-based Haddon matrix. J. Humanit. Logist. Supply Chain Manag. 7, 266--283 (2017).

12. Anparasan, A., Lejeune, M.: Data laboratory for supply chain response models during epidemic outbreaks. Ann. Oper. Res., 270, 53--64 (2018).

13. Anparasan, A., Lejeune, M.: Resource deployment and donation allocation for epidemic outbreaks," Ann. Oper. Res., 283, 9--32 (2019).

14. Ivanov, D., Dolgui, A.: Viability of intertwined supply networks: extending the supply chain resilience angles towards survivability. A position paper motivated by COVID-19 outbreak. Int. J. Prod. Res., 58, 2904--2915 (2020).

15. Ivanov, D.: Viable supply chain model: integrating agility, resilience and sustainability perspectiveslessons from and thinking beyond the COVID-19 pandemic. Ann. Oper. Res. (2020).

16. Ekici, A., Keskinocak, P., Swann, J.: Modeling Influenza Pandemic and Planning Food Distribution. Manuf. Serv. Oper. Manag., 16, 11--27 (2014).

17. Miranda, R., Schaffner, D.: Virus risk in the food supply chain. Curr. Opin. Food Sci., vol. 30, 43--48 (2019).

18. Magalhães, A., Rossi, A., Zattar, I., Marques, M., Seleme, R.: Food traceability technologies and foodborne outbreak occurrences. Br. Food J., vol. 121, $3362--3379$ (2019).

19. Denyer, D., Tranfield, D.: Producing a systematic review. in The Sage handbook of organizational research methods, SAGE Publications Ltd, 671--689 (2009).

20. Christopher, M., Peck, H.: Building the Resilient Supply Chain. Int. J. Logist. Manag., vol. 15, 1--14 (2004).

21. Dolgui, A., Ivanov, D., Sokolov, B.: Ripple effect in the supply chain: an analysis and recent literature. Int. J. Prod. Res., 56, 414--430 (2018).

22. Jüttner, U., Peck, H., Christopher, M.: Supply chain risk management: outlining an agenda for future research. Int. J. Logist. Res., 6, 197--210 (2003).

23. Behzadi, G., O’Sullivan, M., Olsen, T., Zhang, A.: Agribusiness supply chain risk management: A review of quantitative decision models. Omega (United Kingdom), 79, 21--42 (2018).

24. Kleindorfer, P., Saad, G.: Managing disruption risks in supply chains. Prod. Oper. Manag., 14, 53--68 (2005).

25. Vishnu, C., Sridharan, R., Gunasekaran, A., Ram Kumar, P.: Strategic capabilities for managing risks in supply chains: current state and research futurities. J. Adv. Manag. Res. (2019).

26. Deaton, B., Deaton, B.: Food security and Canada's agricultural system challenged by COVID-19. Can. J. Agric. Econ., 1--7 (2020).

27. Richards, T., Rickard, B.: COVID-19 impact on fruit and vegetable markets. Can. J. Agric. Econ., 1--6 (2020).

28. Larue, B.: Labor issues and COVID-19. Can. J. Agric. Econ. Can. d'agroeconomie, 12233 (2020)

29. Hollnagel, E.: Epilogue: RAG: the resilience analysis Grid in Resilience Engineering in Practice: A guidebook, Ashgate Pr., E. Hollnagel, J. Paries, D. Woods, and J. Wreathall, Eds, 275--296 (2011). 
30. Ponomarov, S., Holcomb, M.: Understanding the concept of supply chain resilience. Int. J. Logist. Manag., 20, 124--143 (2009).

31. Wu, T., Huang, S., Blackhurst, J., Zhang, X., Wang, S.: Supply chain risk management: An agentbased simulation to study the impact of retail stockouts. IEEE Trans. Eng. Manag., 60, 676--686 (2013).

32. Schmitt, A., Singh, M.: A quantitative analysis of disruption risk in a multi-echelon supply chain. Int. J. Prod. Econ., 139, 22--32 (2012).

33. Vroegindewey, R., Hodbod, J.: Resilience of Agricultural Value Chains in Developing Country Contexts: A Framework and Assessment Approach. Sustainability, 10, 916, 2018.

34. Behzadi, G., O'Sullivan, M., Olsen, T., Scrimgeour, F., Zhang, A.: Robust and resilient strategies for managing supply disruptions in an agribusiness supply chain. Int. J. Prod. Econ., 191, 207--220 (2017).

35. Bottani, E., Murino, T., Schiavo, M., Akkerman, R.: Resilient food supply chain design: Modelling framework and metaheuristic solution approach. Comput. Ind. Eng., 135, 177--198 (2019).

36. Meuwissen, M., et al., "A framework to assess the resilience of farming systems," Agric. Syst., 176 (2019).

37. Dutta, P., Shrivastava, H.: The design and planning of an integrated supply chain for perishable products under uncertainties: A case study in milk industry. J. Model. Manag., (2020).

38. Aboah, J., Wilson, M., Rich, M., Lyne, M.: Operationalising resilience in tropical agricultural value chains. Supply Chain Manag., 24, 271--300 (2019).

39. Ravulakollu, A., Urciuoli, L., Rukanova, B., Tan, Y., Hakvoort, R.: Risk based framework for assessing resilience in a complex multi-actor supply chain domain. Supply Chain Forum, 19, 266--281 (2018).

40. Das, K.: Integrating lean, green, and resilience criteria in designing a sustainable food supply chain. Proc. Int. Conf. Ind. Eng. Oper. Manag., 2018, 462--473 (2018).

41. Zhu, Q., Krikke, H.: Managing a Sustainable and Resilient Perishable Food Supply Chain (PFSC) after an Outbreak. Sustainability, 12, 5004 (2020).

42. Rozhkov, M., Ivanov, D.: Contingency production-inventory control policy for capacity disruptions in the retail supply chain with perishable products. IFAC-PapersOnLine, 51, 1448--1452 (2018).

43. Yavari, M., Zaker, H.: Designing a resilient-green closed loop supply chain network for perishable products by considering disruption in both supply chain and power networks. Comput. Chem. Eng., 134 (2020).

44. Ye, F., Hou, G., Li, Y., Fu, S.: Managing bioethanol supply chain resiliency: a risk-sharing model to mitigate yield uncertainty risk. Ind. Manag. Data Syst., 118, 1510--1527 (2018).

45. Jabbarzadeh, A., Fahimnia, B., Sheu, J., Moghadam, H.: Designing a supply chain resilient to major disruptions and supply/demand interruptions. Transp. Res. Part B Methodol., 94, 121--149 (2016).

46. O'Leary, D.: Evolving Information Systems and Technology Research Issues for COVID-19 and Other Pandemics. J. Organ. Comput. Electron. Commer., 30, 1--8 (2020).

47. Zavala-Alcívar, A., Verdecho, M.-J. and Alfaro-Saíz, J.-J.: A Conceptual Framework to Manage Resilience and Increase Sustainability in the Supply Chain. Sustainability, 12, 16, 6300 (2020).

48. Fahimni, B., Jabbarzadeh, A.: Marrying supply chain sustainability and resilience: A match made in heaven. Transp. Res. Part E Logist. Transp. Rev., 91, 306--324 (2016).

49. Verdecho, M., Alarcón-Valero, F., Pérez-Perales, D., Alfaro-Saiz, J., Rodríguez-Rodríguez, R.: A methodology to select suppliers to increase sustainability within supply chains. Cent. Eur. J. Oper. Res. (2020).

50. Bai, C. and Sarkis, J.: Integrating sustainability into supplier selection with grey system and rough set methodologies. Int. J. Prod. Econ., 124, 1, 252--264, (2010).

51. Bai, C., Sarkis, J.: Green supplier development: Analytical evaluation using rough set theory. J. Clean. Prod., 18, 1200--1210 (2010).

52. Valipour, S., Safaei, A., Fallah, H.: Resilient supplier selection and segmentation in grey environment. J. Clean. Prod., 207, 1123--1137 (2019).

53. Zimmer, K., Fröhling, M., Schultmann, F.: Sustainable supplier management - a review of models supporting sustainable supplier selection, monitoring and development. Int. J. Prod. Res., 54, 1412-1442 (2016).

54. Yang, S., Xiao, Y., Kuo, Y.: The Supply Chain Design for Perishable Food with Stochastic Demand. Sustainability, 9, 1195 (2017).

55. Zahiri, B., Zhuang, J., Mohammadi, M.: Toward an integrated sustainable-resilient supply chain: A pharmaceutical case study. Transp. Res. Part E Logist. Transp. Rev., 103, 109-142 (2017).

56. Duong, L., Chong, J.: Supply chain collaboration in the presence of disruptions: a literature review. Int. J. Prod. Res., 58, 3488-3507 (2020). 